\title{
Volatile Organic Compounds during Inflammation and Sepsis in Rats
}

\section{A Potential Breath Test Using Ion-mobility Spectrometry}

\author{
Tobias Fink, M.D., Alexander Wolf, M.D., Felix Maurer, D.Sc., Frederic W. Albrecht, M.D., \\ Nathalie Heim, Beate Wolf, Anne C. Hauschild, M.Sc., Bertram Bödeker, Jörg I. Baumbach, Ph.D., \\ Thomas Volk, M.D., Ph.D., Daniel I. Sessler, M.D., Ph.D., Sascha Kreuer, M.D., Ph.D.
}

\begin{abstract}
Background: Multicapillary column ion-mobility spectrometry (MCC-IMS) may identify volatile components in exhaled gas. The authors therefore used MCC-IMS to evaluate exhaled gas in a rat model of sepsis, inflammation, and hemorrhagic shock.

Methods: Male Sprague-Dawley rats were anesthetized and ventilated via tracheostomy for $10 \mathrm{~h}$ or until death. Sepsis was induced by cecal ligation and incision in 10 rats; a sham operation was performed in 10 others. In 10 other rats, endotoxemia was induced by intravenous administration of $10 \mathrm{mg} / \mathrm{kg}$ lipopolysaccharide. In a final 10 rats, hemorrhagic shock was induced to a mean arterial pressure of $35 \pm 5 \mathrm{mmHg}$. Exhaled gas was analyzed with MCC-IMS, and volatile compounds were identified using the BS-MCC/IMS-analytes database (Version 1209; B\&S Analytik, Dortmund, Germany).

Results: All sham animals survived the observation period, whereas mean survival time was $7.9 \mathrm{~h}$ in the septic animals, $9.1 \mathrm{~h}$ in endotoxemic animals, and $2.5 \mathrm{~h}$ in hemorrhagic shock. Volatile compounds showed statistically significant differences in septic and endotoxemic rats compared with sham rats for 3-pentanone and acetone. Endotoxic rats differed significantly from sham for 1-propanol, butanal, acetophenone, 1,2-butandiol, and 2-hexanone. Statistically significant differences were observed between septic and endotoxemic rats for butanal, 3-pentanone, and 2-hexanone. 2-Hexanone differed from all other groups in the rats with shock.

Conclusions: Breath analysis of expired organic compounds differed significantly in septic, inflammation, and sham rats. MCC-IMS of exhaled breath deserves additional study as a noninvasive approach for distinguishing sepsis from inflammation. (ANESTHEsiology 2015; 122:117-26)
\end{abstract}

T HOUSANDS of volatile organic compounds (VOCs) are expelled with each breath. The composition of these VOCs can change with the state of health. ${ }^{1-10}$ Breath analysis has consequently become a promising field of research. One suitable tool for breath analysis is multicapillary column ion-mobility spectrometry (MCC-IMS). The MCC-IMS is a noninvasive and rapid method for detection of VOCs in exhaled breath. The principles of MCC-IMS have been described previously. ${ }^{11,12}$ MCC-IMS is already used extensively for detection of drugs, chemicals, and explosives. ${ }^{13,14}$ But this technique has already been used for evaluation of pulmonary diseases, that is, chronic obstructive pulmonary disease, ${ }^{1-3}$ acute respiratory distress syndrome, ${ }^{4}$ lung cancer, and airway infections. ${ }^{1,6,15}$ Furthermore, it also appears possible to detect volatile metabolites arising from various bacterial species. ${ }^{7-10}$

Based on these results using MCC-IMS for diagnosis of pulmonary diseases and inflammation, the question rises if systemic inflammation and sepsis are also appropriated targets

\section{What We Already Know about This Topic}

- Septic patients are not always readily identified by caregivers, and there is a short window for optimum antibiotic treatment

What This Article Tells Us That Is New

- Exhaled gas from rats given endotoxin compared with the gas from rats with bacterial sepsis was found to be significantly different and different from rats who were in hemorrhagic shock

- Breath analysis appears to be able to distinguish inflammation from infection

for this novel noninvasive device. To our knowledge, only one study from Guamán et al. ${ }^{15}$ used gas chromatography-mass spectrometry to evaluate the systemic inflammatory response to intraperitoneal lipopolysaccharide in rats.

But whether MCC-IMS can be used on exhaled breath as a measure of sepsis and systemic inflammation remains unknown. We therefore compared patterns of exhaled organic compounds in septic, endotoxemic shock (ES),

Submitted for publication November 25, 2013. Accepted for publication July 24, 2014. From the Department of Anesthesiology, Intensive Care, and Pain Therapy, Saarland University Medical Center, Homburg (Saar), Germany (T.F., A.W., F.M., F.W.A., N.H., B.W., T.V., S.K.); Computational Systems Biology Group, Max Planck Institute for Informatics, Saarbrücken, Germany (A.C.H.); B\&S Analytik, BioMedicalCenter, Dortmund, Germany (B.B., J.I.B.); Faculty of Applied Chemistry, Reutlingen University, Reutlingen, Germany (J.I.B.); and Department of Outcomes Research, Cleveland Clinic, Cleveland, Ohio (D.I.S.). 
and sham-control rats during an observation period of $10 \mathrm{~h}$. A further group of pressure-controlled hypotension was used to distinguish between infection, inflammation, and noninfectious shock in exhaled metabolites. Noninfectious shock was included to distinguish changes in VOCs resulting from infection/inflammation versus hypotension alone.

\section{Material and Methods}

\section{Animals}

All experiments were conducted with approval from our Animal Care and Use Committee (Landesamt für Soziales, Gesundheit und Verbraucherschutz; Saarbrücken; Germany) and in accordance with the German Animal Welfare Act. Male Sprague-Dawley rats (200 to $300 \mathrm{~g}$ body weight) were obtained from Charles River (Sulzfeld, Germany) and kept in the institutional animal facility under controlled conditions (temperature $20^{\circ} \pm 2^{\circ} \mathrm{C}$ and $50 \pm 5 \%$ humidity). Animals had free access to water; standard pellet food was withheld for $12 \mathrm{~h}$ before the experiment.

\section{Chemicals}

Pure lipopolysaccharide of Escherichia coli serotype O26:B6 was obtained from Sigma-Aldrich (Munich, Germany).

\section{Surgical Procedures}

Rats were anesthetized with pentobarbital $60 \mathrm{mg} / \mathrm{kg}$ intraperitoneally and positioned on a warming plate; an open tracheotomy was performed to facilitate breathing. The right external jugular vein was catheterized to allow for infusion, and the left carotid artery was catheterized for continuous measurement of mean arterial pressure (MAP) and heart rate (Philips IntelliVue MP20 Junior, Boeblingen, Germany).

Afterward the rats were connected to the respirator (KTR-5 small animal ventilator; Hugo Sachs ElektronikHarvard Apparatus, March-Hugstetten, Germany) and ventilated with highly purified synthetic air (Air Liquid, Ludwigshafen, Germany). The MCC-IMS (type Breath discovery; B\&S Analytik, Dortmund, Germany) was connected to the same tank of synthetic air.

Tidal volume was adapted to a physiological lift of the thorax wall and respiratory rate set to $65 \mathrm{~min}^{-1}$ at an inspiration ratio of $45 \%$ and a positive end-expiratory pressure of 1 to $2 \mathrm{~cm} \mathrm{H}_{2} \mathrm{O}$. General anesthesia was maintained throughout the study with pentobarbital intravenously as needed. The rats were given intravenous isotonic solution at a rate of $10 \mathrm{ml} \mathrm{kg}^{-1} \mathrm{~h}^{-1}$ (Sterofundin ISO; B. Braun, Melsungen, Germany).

\section{Experimental Protocol}

We evaluated four groups of 10 rats each, randomly assigned to sepsis (CLI), ES, hemorrhagic shock (HS), and sham control:

CLI: Sepsis was induced using a modified model of cecal ligation and incision as previously described. ${ }^{16,17}$ The cecum was exteriorized through a midline laparotomy, and the cecum and paracecal blood vessels were ligated below the ileocecal valve. The ligated cecum was incised $1.5 \mathrm{~cm}$ on the antimesenteric side and replaced in the abdomen, and the abdominal wall was closed.

Sham: Sham-operated rats were treated likewise but without ligation and incision.

ES: ES was induced by administration of $10 \mathrm{mg} / \mathrm{kg}$ lipopolysaccharide E. coli serotype O26:B6 intravenously.

HS: A modified pressure-regulated shock model was used as described preciously, ${ }^{18,19}$ but without resuscitation and retransfusion. HS was induced by rapid arterial blood withdrawal by way of the carotid artery with a $\mathrm{MAP}$ of $35 \pm 5 \mathrm{mmHg}$.

Induction of sepsis or sham operation was carried out by the same investigator and subsequently blinded during the observation period. ES and HS groups were also carried out by the same investigator, but blinding was not realizable. When measurements were finished, all surviving rats were killed with an overdose of pentobarbital.

Arterial blood $(0.2 \mathrm{ml})$ was sampled every $2.5 \mathrm{~h}$ for analysis of $\mathrm{pH}$, base excess, lactate, hemoglobin, glucose, partial pressures of oxygen, and carbon dioxide (Radiometer ABL 800 Basic, Willich, Germany). After insertion of the arterial catheter, and $5 \mathrm{~h}$ after induction of CLI, blood samples $(0.5 \mathrm{ml})$ were taken for enzyme-linked immunosorbent assay (ELISA) analysis of pro- and antiinflammatory cytokines.

\section{MCC-IMS Measurements}

We used a Bioscout 2011 MCC-IMS based on a $550 \mathrm{MBq}$ $63 \mathrm{Ni}$ ionization source with an electrical field strength of $300 \mathrm{~V} / \mathrm{cm}$ and equipped with MCC using a general-purpose, slightly polar standard capillary column phase OV-5 (Multichrom, Novosibirsk, Russia).

Before connecting the rats to the MCC-IMS, we measured background concentrations of organic volatile compounds from the respirator for $1 \mathrm{~h}$. Throughout the experiment, the rats were ventilated with synthetic air as described previously. ${ }^{20}$ To avoid any extraneous signals, polytetrafluoroethylene (Bohlender, Grünsfeld, Germany) was used for all external connections, and the MCC-IMS sampling tube was directly connected to the exhalatory line of the respirator. Breath humidity and cluster reactions between ions and water lead to significant changes of the IMS spectra; therefore we used a MCC coupled with an ionmobility spectrometer to avoid this error.

Exhaled gas ( $10 \mathrm{ml}$ per measurement) was collected in the sample loop before entering the multicapillary column of the ion-mobility spectrometer. This arrangement allowed three measurements per hour. The retention time in relation to the preseparation of the MCC, drift time of the ions within the IMS, and the intensity of the analytes were delivered by the MCC-IMS and subsequently identified using the BS-MCC/ IMS-analytes database (Version 1209; B\&S Analytik). 
Peaks representing various VOCs were identified using Visual Now 3.1 (B\&S Analytik). All signals above the threshold of $1 \mathrm{mV}$ to $5 \mathrm{~V}$ (peak range: lower limit is defined as five times over the background noise; the upper limit depends on the saturation of the drift tube) were defined as a peak and characterized by their position with drift time, retention time, and concentration related to the peak intensity.

\section{Cytokine Assay}

Cytokine concentrations were measured by ELISA. Positive controls of each cytokine were measured routinely with each assay (ELISA Antibodies BD OptEIA; BD Biosciences Pharmingen, San Diego, CA).

\section{Statistical Analysis and Signal Processing}

Mathematical and statistical evaluation was carried out using SigmaPlot (version 12.5; Systat Software, Erkrath, Germany).

Based on our previous experience, we confirmed a number of 10 rats per group as sufficient to see clear differences. Animals were randomized in four groups using a random number generator (Excel 2010; Microsoft, Redmond, WA).

Survival time was analyzed using a log-rank model according to Kaplan-Meier, followed by an all-pairwise comparison using Tukey test.

Data were tested for distribution normality (Kolmogorov-Smirnov test) and analyzed using repeated-measures ANOVA, followed by post hoc multiple comparisons with Holm-Sidak method. When appropriate, repeatedmeasures ANOVA on ranks were used. Based on the survival rate, statistical analysis for each volatile compound was performed from 0 to $6 \mathrm{~h}$ in the sham, sepsis, and endotoxemic group.

Hemorrhagic shock group was merely analyzed after $2 \mathrm{~h}$ using one-way ANOVA followed by post hoc multiple comparisons with the Holm-Sidak method. A two-tailed $P$ value of less than 0.05 was considered statistically significant.

\section{Results}

\section{Survival Time, Blood Gas Analysis, and Cytokines}

All sham rats survived the observation period, whereas others died earlier: HS: mean, $2.5 \pm 0.3 \mathrm{~h} ; 95 \% \mathrm{CI}, 1.9$ to $3.1 \mathrm{~h}$; CLI: mean, $7.9 \pm 0.4 \mathrm{~h}$; CI, 7.2 to $8.7 \mathrm{~h}$; and, ES: mean, $9.1 \pm 0.4 \mathrm{~h}$; and CI, 8.3 to $9.9 \mathrm{~h}$. All $P$ values less than 0.001 versus sham (fig. 1).

All blood gas values remained stable and normal in shamoperated rats. In contrast, blood lactate concentrations increased significantly over time in CLI, ES, and HS rats. Arterial base excess and $\mathrm{pH}$ were significantly lower in the CLI and ES groups than sham rats (table 1). Respiratory parameters (partial pressure of oxygen, partial pressure of carbon dioxide, and oxygenation index), hemoglobin, and blood glucose remained within normal ranges throughout the experiment in both groups.
Baseline concentrations of tumor necrosis factor- $\alpha$, interleukin-6, and interleukin-10 were similar at the beginning of the experiment. However, concentrations of all three increased significantly in the septic and endotoxemic rat (table 2).

\section{Hemodynamic Parameters}

Baseline MAP was similar in all groups and remained stable throughout in the sham-operated rats (fig. 2). Induction of HS resulted in a significant decline of MAP. Injection of lipopolysaccharide resulted in an early reduction of MAP from 1 to $2 \mathrm{~h}$ and further at $5 \mathrm{~h}$ and thereafter. MAP gradually declined in the CLI rats, becoming significantly lower than in the sham group after $5 \mathrm{~h}$. The heart rate remained within normal ranges during the entire observation period, without significant differences between the groups.

\section{Multicapillary Column Ion-mobility Spectrometry}

During the experiment, about a hundred different signals between a threshold of $1 \mathrm{mV}$ and $5 \mathrm{~V}$ (peak definition) were detected in exhaled air. Seven signals presented with significant differences between groups during the first $6 \mathrm{~h}$ of the observation period. Those seven were considered potentially useful VOCs for distinguishing among treatments. Figure 3 illustrates the typical IMS chromatogram of 3-pentanone and a three-dimensional plot for this setting.

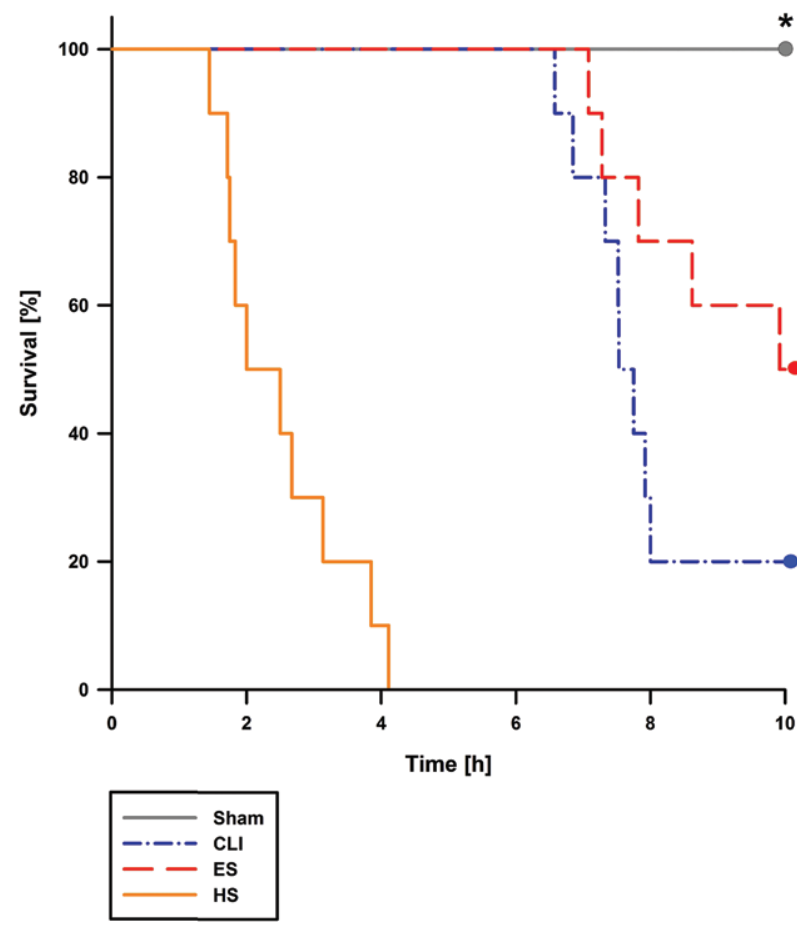

Fig. 1. Survival rate. After hemorrhagic shock (HS), endotoxemic shock (ES), and sepsis (CLI), mean survival time was significantly decreased compared with sham control. ${ }^{*} P<0.001$ for sham versus HS, ES, and CLI. 
Table 1. Arterial Blood Gas Analysis

\begin{tabular}{|c|c|c|c|c|c|}
\hline & $\mathrm{Oh}$ & $2.5 \mathrm{~h}$ & $5 \mathrm{~h}$ & $7.5 \mathrm{~h}$ & $10 \mathrm{~h}$ \\
\hline \multicolumn{6}{|c|}{ Survival rate $(\mathrm{N}=)$} \\
\hline Sham & 10 & 10 & 10 & 10 & 10 \\
\hline CLI & 10 & 10 & 10 & 7 & 2 \\
\hline ES & 10 & 10 & 10 & 8 & 5 \\
\hline HS & 10 & 5 & & & \\
\hline \multicolumn{6}{|l|}{$\mathrm{pH}$} \\
\hline Sham & 7.39 (7.34-7.49) & $7.42(7.38-7.45)$ & $7.41(7.35-7.48)$ & $7.42(7.36-7.54)$ & 7.39 (7.35-7.42) \\
\hline CLI & 7.37 (7.31-7.44) & $7.35(7.20-7.44)$ & $7.26^{*}(7.16-739)$ & $7.23^{*} \dagger(7.13-7.40)$ & $7.23(7.23-7.26)$ \\
\hline ES & 7.41 (7.32-7.52) & $7.36(7.28-7.46)$ & 7.36 (7.14-7.52) & $7.30(7.11-7.46)$ & 7.29 (7.25-7.30) \\
\hline HS & $7.40(7.30-7.50)$ & $7.41(7.30-7.54)$ & & & \\
\hline \multicolumn{6}{|c|}{ Base excess } \\
\hline Sham & $-0.5(-6.0$ to 5.7$)$ & $-3.6(-6.1$ to -1.8$)$ & $-3.9(-5.4$ to -2.6$)$ & $-4.0(-7.2$ to -1.5$)$ & $-3.8(-6.9$ to -3.2$)$ \\
\hline CLI & $-1.1(-8.4$ to 5.4$)$ & $-5.6(-12.3$ to 0.2$)$ & $-10.1^{*} \dagger(-17.9$ to -2.1$)$ & $-14.8^{*} \dagger(-25.9$ to -7.1$)$ & $-15.0(-18.0$ to -12.0$)$ \\
\hline ES & $2.3(-2.4$ to 6.1$)$ & $-5.1(-9.4$ to 0.0$)$ & $-6.0^{*} \dagger(-14.4$ to 0.7$)$ & $-11.6^{*} \dagger(-23.8$ to -1.7$)$ & $-10.9(-13.6$ to -80$)$ \\
\hline HS & $2.5(-0.2$ to 5.8$)$ & $-5.7(-12.3$ to -0.6$)$ & & & \\
\hline \multicolumn{6}{|l|}{ Lactate } \\
\hline Sham & $0.9(0.5-1.6)$ & $0.6(0.5-0.8)$ & $0.9(0.6-1.4)$ & $0.7(0.4-1.1)$ & $0.6(0.4-0.9)$ \\
\hline CLI & $0.9(0.5-1.8)$ & $1.1(0.6-1.8)$ & $2.4(1.0-4.7)$ & $4.1^{*} \dagger(1.3-7.2)$ & $6.2(5.2-7.2)$ \\
\hline ES & $0.7(0.5-1.0)$ & $1.0(0.5-1.4)$ & $2.6^{*} \dagger(1.4-5.3)$ & $4.9^{*}+(3.0-9.4)$ & $4.5(3.9-5.4)$ \\
\hline HS & $0.6(0.4-1.0)$ & $3.2(2.2-6.0)$ & & & \\
\hline \multicolumn{6}{|c|}{ Partial pressure of oxygen } \\
\hline Sham & $82.5(59.1-119)$ & 75.8 (63.7-87.2) & $82.1(41.5-131)$ & $77.8(50.7-154)$ & $79.1(61.2-123)$ \\
\hline CLI & $73.1(59.8-121)$ & $79.4(48.8-99.7)$ & 82.7 (47.8-95.2) & $73.0(68.1-87.0)$ & $77.6(46.2-93.4)$ \\
\hline ES & $83.9(51.5-127)$ & $75.2(58.5-105)$ & $91.9(60.7-166)$ & $87.7(85.1-127)$ & $80.6(68.9-126)$ \\
\hline HS & $72.1(35.6-100)$ & $73.0(50.0-123)$ & & & \\
\hline \multicolumn{6}{|c|}{ Partial pressure of carbon dioxide } \\
\hline Sham & $35.1(24.0-40.9)$ & $31.3(25.3-37.9)$ & $30.9(22.5-37.1)$ & $29.4(18.2-41.6)$ & $32.0(26.0-40.0)$ \\
\hline CLI & $37.6(30.4-44.2)$ & $32.4(23.9-39.4)$ & $32.9(25.7-43.7)$ & $24.5(17.7-35.6)$ & $29.7(28.4-31.0)$ \\
\hline ES & $36.6(23.3-44.9)$ & $33.2(28.2-38.9)$ & $34.6(20.4-44.5)$ & $29.0(17.0-36.4)$ & $24.2(21.6-28.0)$ \\
\hline HS & $37.7(30.7-47.8)$ & $28.1(19.4-31.0)$ & & & \\
\hline \multicolumn{6}{|c|}{ Oxygen index } \\
\hline Sham & $393(281-567)$ & $361(303-415)$ & $391(197-623)$ & $370(279-480)$ & $382(241-633)$ \\
\hline CLI & $348(285-576)$ & $378(246-661)$ & $394(232-475)$ & 315 (227-405) & 371 (324-414) \\
\hline ES & $400(245-480)$ & $358(301-537)$ & $438(279-500)$ & 419 (289-790) & $384(343-504)$ \\
\hline HS & $343(257-585)$ & 348 (469-619) & & & \\
\hline
\end{tabular}

Data are given as means $\pm 95 \%$ Cls. Arterial blood gas analysis revealed normal baseline values for pH, base excess, lactate, partial pressure of oxygen, and carbon dioxide. Lactate values increase significantly, and $\mathrm{pH}$ and base excess decrease significantly over time, when compared with sham control. Respiratory parameters: partial pressure of oxygen and carbon dioxide as oxygenation index (partial pressure of oxygen/oxygen fraction) remained within normal ranges throughout the experiment. Statistical analysis was performed from 0 to $7.5 \mathrm{~h}$.

${ }^{*} P<0.05$ vs. sham group. $\dagger P<0.05$ vs. corresponding baseline.

$\mathrm{CLI}=$ sepsis; $\mathrm{ES}$ = endotoxemic shock; $\mathrm{HS}$ = hemorrhagic shock.

With the BS-MCC/IMS-analytes database (Version 1209), all seven potential compounds could be identified according to their retention time and drift time. All these VOCs are shown in table 3.

As a result of the measured survival time (fig. 1), the statistical analysis of each VOC was performed at $0,2,4$, and $6 \mathrm{~h}$ in the sham, CLI, and ES (each $\mathrm{n}=10$ per group at these time points). Sham-operated rats presented with approximately stable concentrations of all VOCs throughout the observation period. During the experiment, seven VOCs decreased significantly in lipopolysaccharide-treated rats, when compared with sham. At $2 \mathrm{~h}$ and thereafter 1 -propanol $(P<0.04)$, butanal $(P<0.001)$, acetophenone $(P<0.022), 1,2$-butandiol $(P<$ $0.001)$, 3-pentanone $(P<0.001)$, acetone $(P<0.001)$, and 2-hexanone $(P<0.001)$, all decreased (table 3 and figs. 4-6).
In the septic rats, though, only two compounds decreased significantly. 3-Pentanone $(P<0.001)$ and acetone $(P=0.02)$ decreased at $6 \mathrm{~h}$ (table 3 and figs. 4 and 5).

Overall, there were significant differences between ES and CLI in the concentrations of three VOCs: butanal $(P<0.001$ at $2 \mathrm{~h}$ and thereafter), 3-pentanone $(P<0.001$ at $2 \mathrm{~h}$ and thereafter), and 2 -hexanone $(P<0.001$ at $2 \mathrm{~h}$ and thereafter (table 3 and figs. 4 and 6).

Noninfectious shock was included to distinguish changes in VOCs resulting from infection or inflammation versus hypotension alone. Due to the high mortality in this group, a single statistical evaluation was performed at $2 \mathrm{~h}$ after induction of HS:

There was significant increase in 2-hexanone $(P<0.001)$ when compared with all other groups, and for butanal 
Table 2. Cytokine Response

\begin{tabular}{|c|c|c|}
\hline & $\mathrm{Oh}$ & $5 \mathrm{~h}$ \\
\hline & (N = 10 per Group) & ( $\mathrm{N}=10$ per Group) \\
\hline \multicolumn{3}{|c|}{ Tumor necrosis factor- $\alpha, \mathrm{pg} / \mathrm{ml}$} \\
\hline Sham & $0.0(0.0-0.0)$ & $0.0(0.0-0.0)$ \\
\hline CLI & $0.1(0.0-0.3)$ & $17.9(0.0-37.1)^{\star}$ \\
\hline ES & $0.2(0.0-2.0)$ & $27.10(2.3-62.1)^{\star}$ \\
\hline \multicolumn{3}{|c|}{ Interleukin-10, pg/ml } \\
\hline Sham & $0.0(0.0-0.0)$ & $0.0(0.0-0.0)$ \\
\hline CLI & $5.1(0.0-16.5)$ & $312(84.4-784)^{\star}$ \\
\hline ES & $2.3(0.0-7.5)$ & $184(10.0-365)^{\star}$ \\
\hline \multicolumn{3}{|c|}{ Interleukin-6, pg/ml } \\
\hline Sham & 374 (279-677) & $377(267-505)$ \\
\hline CLI & $375(346-404)$ & $11,223(1,223-31,790)^{*}$ \\
\hline ES & $315(160-412)$ & $17,663(1,246-41,598)^{\star}$ \\
\hline
\end{tabular}

CLI and ES significantly increased tumor necrosis factor- $\alpha$, interleukin-10, and interleukin-6 compared with sham-operated rats. Data are given as means $\pm 95 \% \mathrm{Cl}(\mathrm{n}=10$ per group at 0 and $5 \mathrm{~h})$.

${ }^{*} P<0.001$ vs. baseline and corresponding sham group.

$\mathrm{CLI}$ = sepsis; $\mathrm{ES}$ = endotoxemic shock; HS = hemorrhagic shock.

$(P<0.006)$, 3-pentanone $(P<0.001)$, and acetone $(P<0.001)$ when compared with endotoxemia. However, none of the VOCs decreased significantly compared with sham (table 3).

Table 4 gives an overview of changes in volatile compounds with significant differences after $6 \mathrm{~h}$.

\section{Discussion}

Currently, diagnosis of sepsis and septic shock relies on nonspecific physiological signs, and early appropriate treatment remains of prime importance. Common diagnostic tools, such as blood culture techniques, procalcitonin, ELISA, or polymerase chain reaction, harbor a series of drawbacks and limitations. ${ }^{21-26}$ MCC-IMS may prove to be an innovative tool to complement conventional diagnostic techniques. ${ }^{15}$ Major advantages of the technique lie in its noninvasive character and near-real-time bedside analysis. ${ }^{8}$

We are aware of only a single previous study in which expired gas was used to detect a systemic inflammatory response. ${ }^{15} \mathrm{In}$ that study, IMS and gas chromatography-mass spectrometry were used to evaluate the systemic inflammatory response to intraperitoneal lipopolysaccharide in rats. Our use of MCC-IMS technology for VOC assessment of sepsis appears to be novel.

We observed a total of 100 signals in exhaled air, between a threshold of $1 \mathrm{mV}$ and $5 \mathrm{~V}$, which was defined as peak range. Seven VOCs presented with significant difference between the investigated groups during the first $6 \mathrm{~h}$ of the experiment and have to be chosen as potential VOCs to distinguish between research groups.

All detected compounds could be identified; the most were ketones, hydrocarbons, alcohols, and ethers. Previous investigators, using different methodologies, found similar compounds in the breath of humans, ${ }^{27,28}$ rats, ${ }^{15}$ and mice ${ }^{29}$ and also in the headspace samples of bacteria cultures. ${ }^{7,8,10,30}$
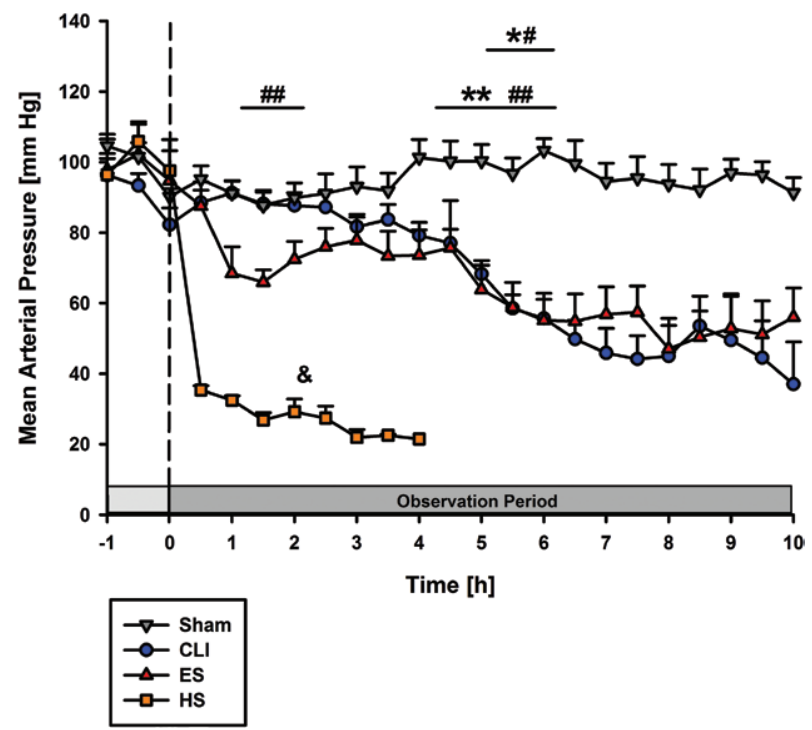

Fig. 2. Mean arterial pressure was significantly lower in the hemorrhagic shock (HS) than in any of the other groups. In endotoxemic shock (ES) and sepsis (CLI) groups, mean arterial pressure decreased over time throughout the experiment compared with sham control. Statistical analysis for sham, $\mathrm{CLI}$, and ES was performed from 0 to $6 \mathrm{~h}$ : ${ }^{\star} P<0.05$ for sham versus CLI. ${ }^{\star \star} P<0.05$ for sham versus ES. \#P<0.05 for CLI versus corresponding baseline. \#\#P $<0.05$ for ES versus corresponding baseline. Statistical analysis for HS was performed at $2 \mathrm{~h}: \& P<0.05$ for HS versus all other groups. Data are given as means \pm SEMs $(n=10$ per group at the beginning of the experiment).

Our focus, though, was not on peak identity, but in differences between sepsis, inflammation, and shock.

Our experimental model of fulminant four-quadrant peritonitis presumably better represents clinical sepsis than lipopolysaccharide endotoxemia, but also poses several problems. During CLI sepsis, rats presented with three clinical entities: infection, inflammation, and shock. To distinguish among them, we used two further models: one with a systemic inflammatory response induced by lipopolysaccharide and another with a pressure-controlled HS.

In comparison with untreated animals, most volatile compounds detected in sepsis and inflammation animals declined over time, as did hemodynamic compensation. However, none of these compounds similarly declined during HS; in contrast, HS was the only condition associated with an increase in VOCs. Also surprisingly, the "sterile" inflammation after injection of lipopolysaccharide seemed to have more altered the most VOCs than the complex model of polymicrobial sepsis. Thus, the observed alterations in volatile compounds during sepsis are unlikely to be the result of hemodynamic decompensation, but seem more likely due to factors specific to sepsis, inflammation, or consequent pulmonary impairments. Furthermore, all animals presented with a normal oxygenation index during the experiment, so the distinction between groups is unlikely influenced by the degree of lung injury. 

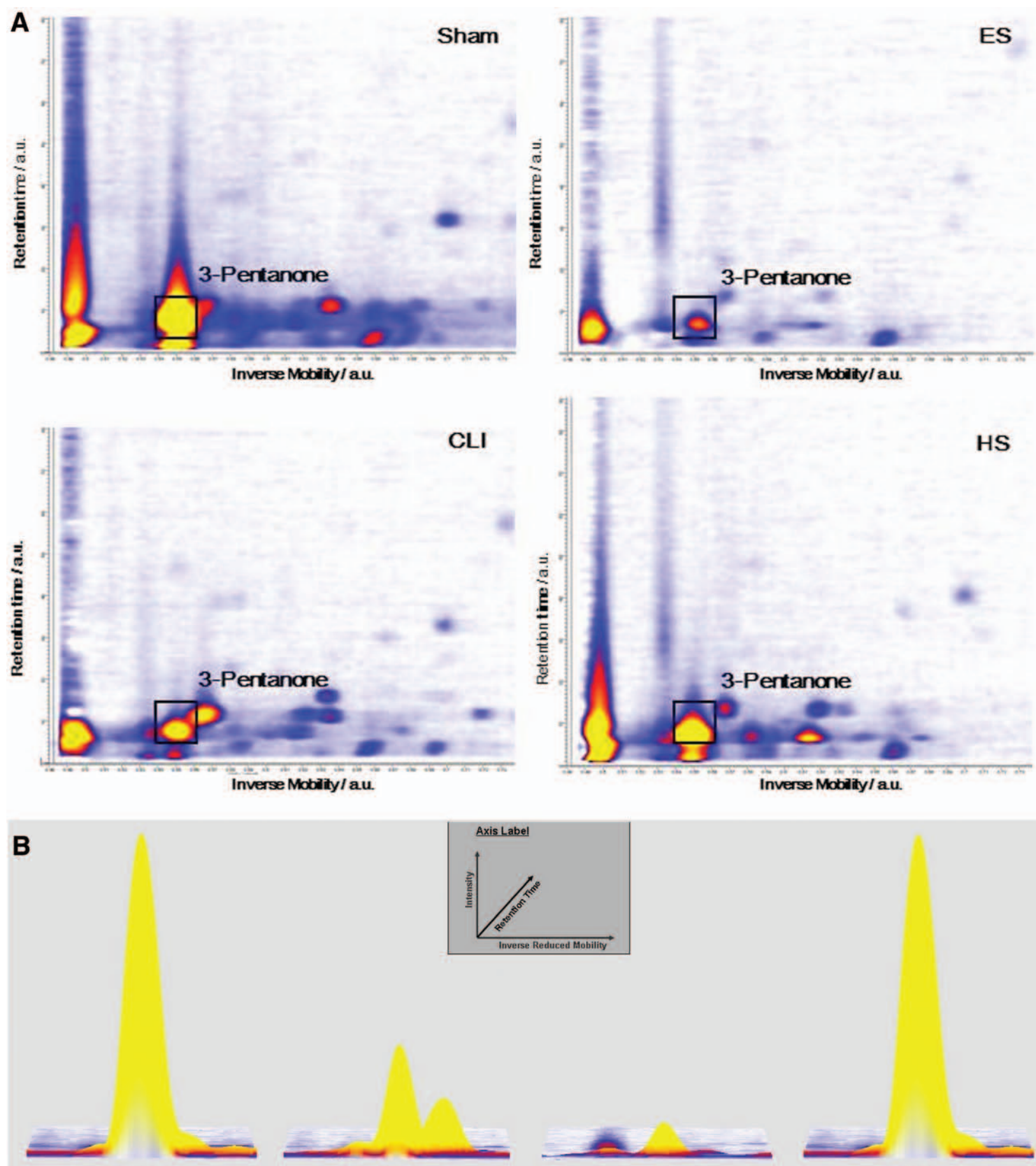

Sham

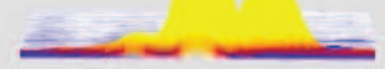

CLI

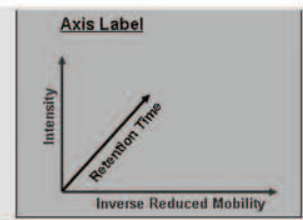

Fig. 3. Ion-mobility spectrometry chromatogram of 3-pentanone. (A) Shows a typical ion-mobility spectrometer chromatogram for, respectively, individual rats in the sham, sepsis (CLI), endotoxemic shock (ES), and hemorrhagic shock (HS) groups after $4 \mathrm{~h}$. (B) A three-dimensional plot of the same rats. Signals above a threshold of $1 \mathrm{mV}$ defined a peak. The peaks were characterized by their position in the ion-mobility spectrometry chromatogram, using the inverse reduced mobility (axis of abscissa; $1 / \mathrm{K}_{0}$ value - which is proportional to the drift time of the ions) and the retention time (axis of ordinates) as well as the peak expansion. Subsequently, peaks were identified according to database BS-multicapillary column/ion-mobility spectrometry-analytes (Version 1209; B\&S Analytik, Dortmund, Germany). For visualization, 3-pentanone is labeled as representative peak in this setting. Comparing the 3-pentanone peak, the drift time of $0.551 \mathrm{Vs} / \mathrm{cm}^{2}$, and a retention time of $8.2 \mathrm{~s}$ are equal in all chromatograms. The peak intensity after $4 \mathrm{~h}$ was $685 \mathrm{mV}$ for sham, $370 \mathrm{mV}$ for CLI, $60 \mathrm{mV}$ for $\mathrm{ES}$, and $585 \mathrm{mV}$ for HS for this peak and is given as difference in color in $A$ and size in $B$. 
Table 3. Identification and Changes in MCC-IMS Peaks

\begin{tabular}{|c|c|c|c|c|c|c|}
\hline & $\mathrm{Oh}$ & $2 \mathrm{~h}$ & $4 \mathrm{~h}$ & $6 \mathrm{~h}$ & $8 \mathrm{~h}$ & $10 \mathrm{~h}$ \\
\hline \multicolumn{7}{|c|}{ Survival rate ( $\mathrm{N}=)$} \\
\hline Sham & 10 & 10 & 10 & 10 & 10 & 10 \\
\hline CLI & 10 & 10 & 10 & 10 & 3 & 2 \\
\hline ES & 10 & 10 & 10 & 10 & 7 & 5 \\
\hline HS & 10 & 6 & 2 & & & \\
\hline \multicolumn{7}{|c|}{ 1-Propanol (CAS 71-23-8) } \\
\hline Sham & $29.3(13.4-60.9)$ & $31.9(9.8-72.1)$ & $30.6(8.5-71.7)$ & $28.3(7.4-61.2)$ & 26.7 (7.3-55.2) & $26.2(7.2-46.5)$ \\
\hline CLI & $31.2(16.0-70.2)$ & $30.1(10.9-62.8)$ & $22.7(7.3-42.9)$ & 14.6† (6.9-22.1) & $16.7(10.4-29.1)$ & $12.7(9.3-16.0)$ \\
\hline ES & $24.0(6.3-51.3)$ & $15.8^{*}(5.4-38.8)$ & $10.9^{*}(4.3-21.7)$ & $10.6^{\star}(6.1-18.1)$ & $12.5(9.8-17.9)$ & $14.3(10.5-23.3)$ \\
\hline HS & $31.8(24.4-47.0)$ & $32.1(26.4-51.5)$ & 35.7 (26.9-47.2) & & & \\
\hline \multicolumn{7}{|c|}{ Butanal (CAS 123-72-8) } \\
\hline Sham & $11.8(6.1-15.8)$ & $13.4(6.3-18.1)$ & 13.6 (5.9-19.8) & 12.7 (4.7-19.0) & $12.8(4.5-20.6)$ & $13.2(4.7-20.8)$ \\
\hline CLI & $12.1(8.1-15.3)$ & $12.8 \ddagger(6.9-16.9)$ & $11.8 \ddagger(9.7-13.5)$ & $10.0 \ddagger(6.0-12.4)$ & $10.1(8.3-12.1)$ & $9.7(8.8-10.6)$ \\
\hline ES & $8.3(5.8-15.4)$ & $6.9^{*}(4.5-12.0)$ & $6.2^{*}(4.2-9.6)$ & $6.3^{*}(4.6-9.3)$ & $5.8(4.7-8.9)$ & $5.2(4.0-6.9)$ \\
\hline HS & $11.3(7.0-18.3)$ & $13.9 \ddagger(6.5-24.1)$ & $21.3(8.4-30.7)$ & & & \\
\hline \multicolumn{7}{|c|}{ Acetophenone (CAS 98-86-2) } \\
\hline Sham & $3.8(1.7-6.1)$ & $4.5(1.6-8.3)$ & $5.1(1.7-13.0)$ & $4.6(1.9-10.5)$ & $5.1(1.6-14.1)$ & $5.0(1.7-11.0)$ \\
\hline CLI & $4.0(1.8-6.1)$ & $3.6(1.7-5.2)$ & $2.8(1.0-4.1)$ & $2.6(1.7-4.6)$ & $3.3(2.1-4.4)$ & $3.4(3.0-3.9)$ \\
\hline ES & $2.7(1.6-7.1)$ & $2.0^{*}(1.1-2.9)$ & $1.9^{*}(1.5-2.4)$ & $1.9^{*}(1.1-2.7)$ & $2.1(1.5-2.6)$ & $2.0(1.7-2.2)$ \\
\hline HS & $3.4(2.2-6.6)$ & $3.1(1.9-6.5)$ & $2.8(2.8-2.8)$ & & & \\
\hline \multicolumn{7}{|c|}{ 1,2-Butandiol (CAS 584-03-2) } \\
\hline Sham & $4.3(1.5-9.0)$ & $4.7(2.1-8.8)$ & $4.7(1.8-9.3)$ & $4.4(1.8-7.5)$ & $4.7(2.2-10.3)$ & $4.8(2.0-8.2)$ \\
\hline CLI & $4.1(2.5-5.8)$ & $4.0(1.9-6.1)$ & $3.6(1.8-5.5)$ & $3.5(1.9-5.0)$ & $3.0(2.0-4.3)$ & $2.3(2.0-2.5)$ \\
\hline ES & $2.9(1.6-5.1)$ & $2.4^{*}(1.3-3.6)$ & $2.3^{*}(1.7-2.8)$ & $2.5^{\star}(1.6-3.1)$ & $2.4(1.2-3.0)$ & $2.6(1.8-3.0)$ \\
\hline HS & $2.8(1.9-4.4)$ & $2.7(1.8-4.4)$ & $2.3(1.9-2.6)$ & & & \\
\hline \multicolumn{7}{|c|}{ 3-Pentanone (CAS 96-22-0) shown in figure 4} \\
\hline Sham & 481 (309-658) & $541(215-753)$ & $528(173-785)$ & 499 (107-767) & $485(157-779)$ & $482(141-769)$ \\
\hline CLI & $495(319-736)$ & $489 \ddagger(232-655)$ & $353 \neq(94.2-553)$ & $213^{*}+(80.8-293)$ & $189(129-224)$ & $179(113-244)$ \\
\hline ES & $404(238-929)$ & $153^{*} \dagger(131-432)$ & $77.8^{*}+(28.3-304)$ & $75.8^{*}+(33.3-240)$ & $69(32-181)$ & $67(43-135)$ \\
\hline HS & $553(204-700)$ & $654 \ddagger(371-697)$ & $576(558-585)$ & & & \\
\hline \multicolumn{7}{|c|}{ Acetone (CAS 67-64-1) shown in figure 5} \\
\hline Sham & $118(54.2-210)$ & $163(31.4-303)$ & $172(27.8-361)$ & $154(25.9-325)$ & $155(21.9-338)$ & $153(19.8-320)$ \\
\hline CLI & $126(53.6-286)$ & $125(44.9-218)$ & $79.4^{\star}(22.8-143)$ & $46.3^{*} \dagger(22.5-64.3)$ & $44(36.2-49.5)$ & $43(33.7-52.2)$ \\
\hline ES & $106(31.2-209)$ & $58.8^{*}(21.0-149)$ & $33.5^{\star}(21.1-62.2)$ & $28.6^{\star} \dagger(21.7-48.7)$ & $29(22.2-38.8)$ & $38(24.4-79.5)$ \\
\hline HS & 167 (23.9-358) & $217 \ddagger(130-319)$ & $158(140-167)$ & & & \\
\hline \multicolumn{7}{|c|}{ 2-Hexanone (CAS 591-78-6) shown in figure 6} \\
\hline Sham & $21.3(13.3-29.7)$ & $22.2(10.4-30.9)$ & 20.7 (9.0-29.1) & 19.5 (9.3-28.8) & $19.3(8.6-30.7)$ & $19.0(7.2-29.7)$ \\
\hline CLI & $22.9(18.6-31.3)$ & $20.8 \ddagger(14.4-26.9)$ & $18.2 \ddagger(9.6-22.7)$ & 16.0† (8.0-20.0) & $19.7(13.0-25.9)$ & $18.0(13.2-22.7)$ \\
\hline ES & $18.3(10.5-33.7)$ & $12.6^{*}(7.1-18.2)$ & $10.5^{\star}(6.0-15.0)$ & $11.3^{*} \dagger(7.9-14.5)$ & $12.1(9.5-14.6)$ & $13.7(9.9-20.6)$ \\
\hline HS $\ddagger$ & $21.0(17.7-27.0)$ & $27.6 \S(21.0-33.1)$ & 33.8 (29.0-43.2) & & & \\
\hline
\end{tabular}

Data are given as means $\pm 95 \% \mathrm{Cl}$. Seven volatile organic compounds with significant changes for peak intensities among the groups were found during the experiment (presented in table 3). Three of them were illustrated in figures 4-6. Statistical analysis was performed from 0 to $6 \mathrm{~h}$.

${ }^{*} P<0.05$ vs. sham group. $\dagger P<0.05$ vs. corresponding baseline. $¥ P<0.05$ vs. LPS. $\S P<0.05$ vs. all other groups.

$\mathrm{CAS}=$ chemical abstract service registry number; $\mathrm{CLI}=$ sepsis; $\mathrm{ES}=$ endotoxemic shock; $\mathrm{HS}$ = hemorrhagic shock; MCC-IMS = multicapillary column ion-mobility spectrometry.

A detailed peak examination revealed an early and strongly reduced release of ketones, acetone, and 3-pentanone during sepsis and inflammation. Our findings are consistent with previous reports showing that blood ketone bodies and the ketogenic capacity of the liver are inhibited during sepsis in rats. ${ }^{31,32}$ These findings seem to be independent of nutritional conditions because fasting before and during sepsis did not result in hypoglycemia. ${ }^{32}$ Instead, increased tumor necrosis factor- $\alpha$ and interleukin-6 plasma concentrations may mediate ketogenic impairment. ${ }^{33}$

Volatile acetone decreased over time in sepsis, inflammation, and HS, suggesting a hemodynamic dependence. But interestingly, other studies reported an increased acetone in exhaled breath of patients with heart failure, associated with an increase in blood brain natriatic peptide concentration. ${ }^{34,35}$ It thus seems unlikely that reduced acetone concentrations result from cardiac decompensation.

Guamán et al. ${ }^{15}$ selected acetone and a further 14 volatile compounds as possible compounds that can be potentially used to separate healthy rats from endotoxemic rats $24 \mathrm{~h}$ after lipopolysaccharide treatment using solid phase microextraction gas chromatography-mass spectrometry Schubert et al. ${ }^{35}$ reported that $n$-pentane concentrations are higher and that acetone 


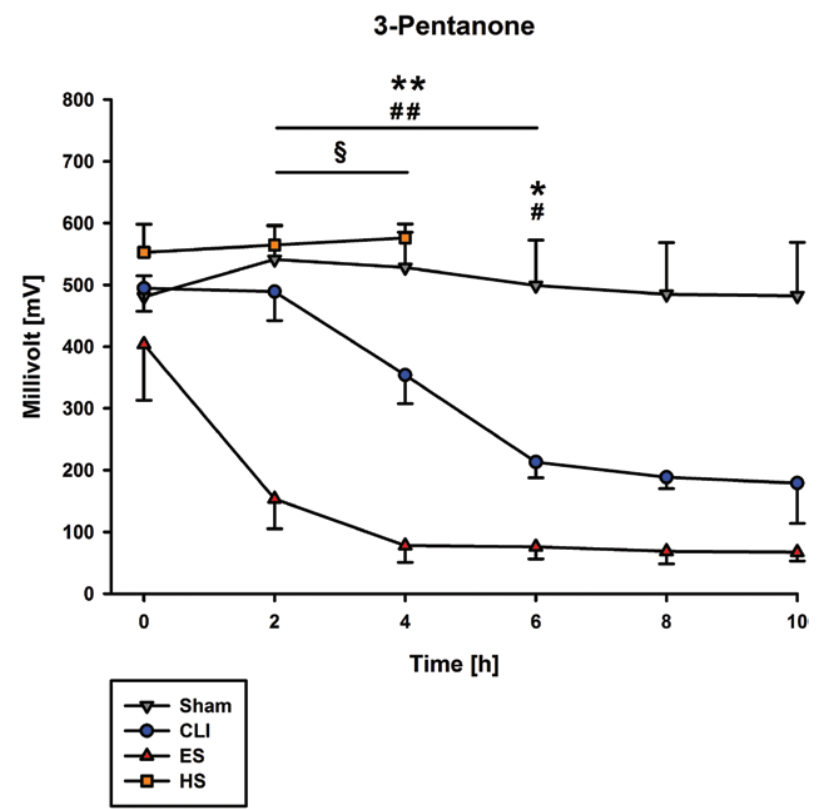

Fig. 4. Peak course of 3-pentanone. For 3-pentanone, sham and hemorrhagic shock (HS) rats exhibited stable signal strength during the experiment. In endotoxemic shock (ES) and sepsis (CLI), 3-pentanone concentrations declined during the observation period. Statistical analysis was performed from 0 to $6 \mathrm{~h}$ : ${ }^{\star} P<0.05$ for sham versus CLI. ${ }^{\star \star} P<0.05$ for sham versus ES. $\S P<0.05$ for CLI versus ES. $\# P<0.05$ for CLI versus corresponding baseline. $\# \# P<0.05$ for ES versus corresponding baseline. Data are given as means \pm SEMs.

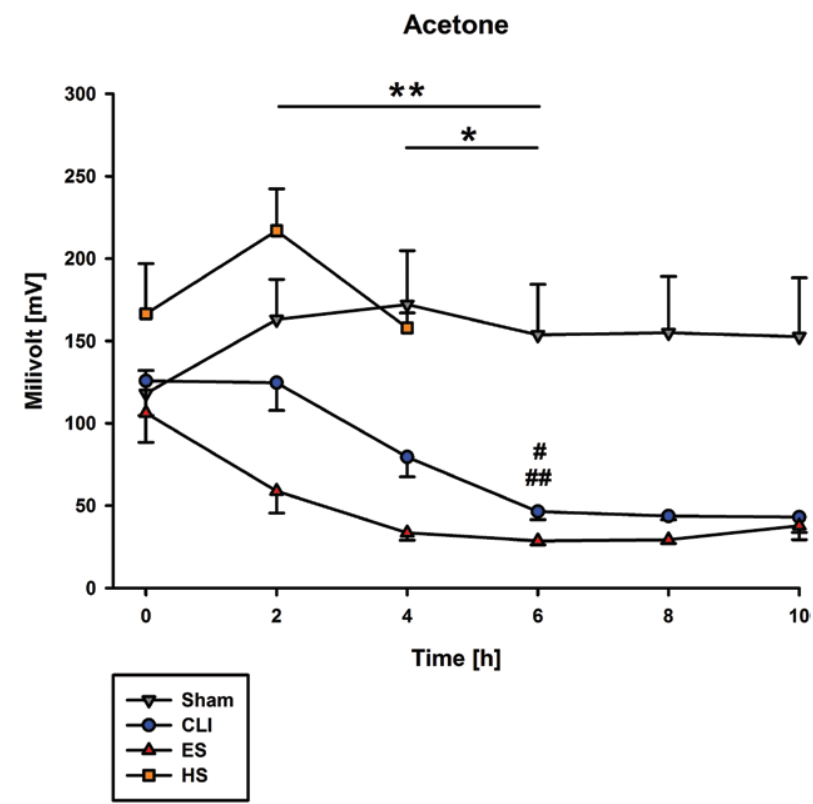

Fig. 5. Peak course of acetone. Examples of an acetone peak declining during hemorrhagic shock (HS), endotoxemic shock (ES), and sepsis (CLI). Statistical analysis was performed from 0 to 6 h: ${ }^{\star} P<0.05$ for sham versus CLI. ${ }^{\star \star} P<0.05$ for sham versus ES. \#P<0.05 for CLI versus corresponding baseline. $\# \# P<0.05$ for ES versus corresponding baseline. Data are given as means \pm SEMs.

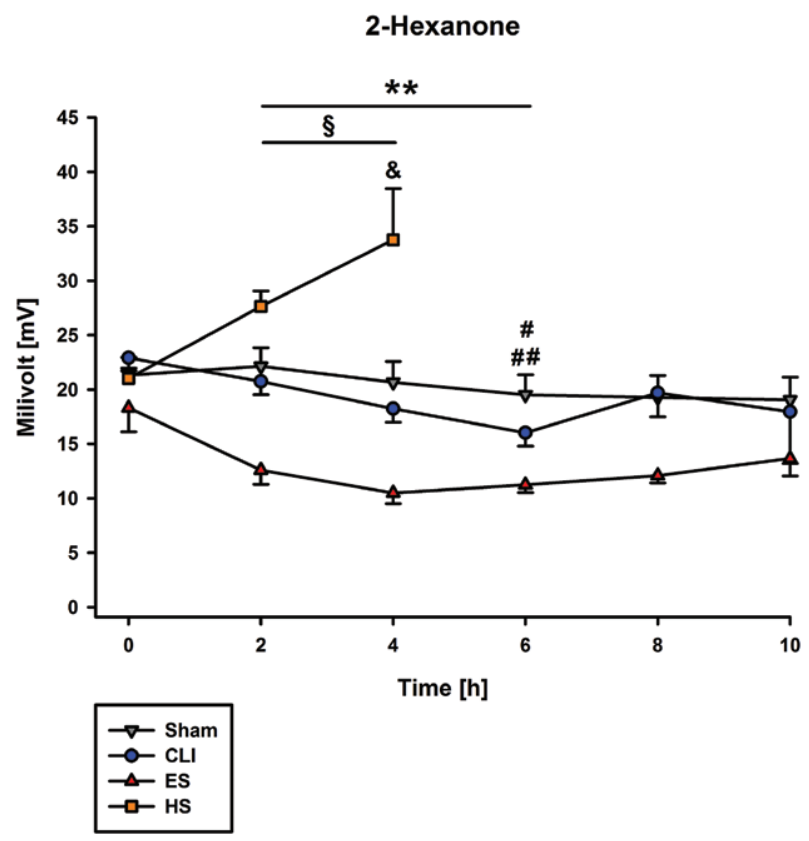

Fig. 6. Peak course of 2-hexanone. 2-Hexanone increased significantly more after induction of hemorrhagic shock (HS) than other treatments. 2-Hexanone decreased in endotoxemic shock (ES) compared with sham control and sepsis (CLI). Statistical analysis was performed from 0 to $6 \mathrm{~h}:{ }^{* \star} P<$ 0.05 for sham versus ES. $\S P<0.05$ for CLI versus ES. \#P< 0.05 for CLI versus corresponding baseline. \#\#P $<0.05$ for ES versus corresponding baseline. Statistical analysis for HS was performed at $2 \mathrm{~h}: \& P<0.05$ for HS versus all other groups. Data are given as means \pm SEMs.

Table 4. Overview of Changes in Volatile Compound Profiles

\begin{tabular}{lcccccccc}
\hline & & 1-Propanol & 3-Pentanone & Acetone & \multicolumn{2}{c}{ 2-Hexanone } \\
\cline { 2 - 8 } & $2 \mathrm{~h}$ & $6 \mathrm{~h}$ & $2 \mathrm{~h}$ & $6 \mathrm{~h}$ & $2 \mathrm{~h}$ & $6 \mathrm{~h}$ & $2 \mathrm{~h}$ & $6 \mathrm{~h}$ \\
\hline Sham & & $\rightarrow$ & & $\rightarrow$ & & $\rightarrow$ & & $\rightarrow$ \\
CLI & & $\downarrow$ & & $\downarrow$ & & $\downarrow$ & & $\downarrow$ \\
ES & & $\rightarrow$ & & $\downarrow$ & & $\downarrow$ & & $\downarrow$ \\
HS & $\rightarrow$ & & $\rightarrow$ & & $\rightarrow$ & & $\uparrow$ & \\
\hline
\end{tabular}

Four volatile organic compounds displayed significant differences for $\mathrm{CLI}$ or ES after $6 \mathrm{~h}$, when compared with corresponding baseline values. Two hours after HS, 2-hexanone was associated with a significant increase in intensity compared with baseline. Significant changes in volatile compound profiles are given as directional arrows: $\rightarrow$ stable, $\downarrow$ decline, $\uparrow$ increase.

$\mathrm{CLI}$ = sepsis; $\mathrm{ES}$ = endotoxemic shock; HS = hemorrhagic shock.

concentrations are lower in the blood of mechanically ventilated septic patients than in healthy controls. However, GC/ MS revealed no differences in the concentration of either substance in the breath of the patient groups. In contrast, previous studies showed increased concentrations of acetone, dimethyl sulfide, 2-butanone, and 2-pentanone in the breath of patients with liver cirrhosis and in the headspace samples of different bacteria. ${ }^{8,29,36}$ The extent to which any of these VOCs might serve as useful diagnostic criteria for sepsis thus remains unclear.

Our study is limited in so far as rodent models only partially correlate with human conditions. ${ }^{37}$ However, the sepsis 
and the inflammation model we chose are standard ones that have been used in many previous studies. A more important limitation is that we do not know whether expired breath markers of inflammation and sepsis can detect the conditions in humans before they are otherwise clinically apparent.

In summary, MCC-IMS analysis of expired gas may help identify sepsis or inflammation. Future studies should evaluate plausible mechanisms for changes in VOC quantities and which breath profiles best indicate a septic or inflammatory state. Thereafter, breath analysis for sepsis and inflammation needs to be confirmed in humans, and its sensitivity and specificity determined.

\section{Acknowledgments}

The authors thank Jan Baumbach, Ph.D. (Department of Mathematics and Computer Science, University of Southern Denmark, Odense, Denmark), for his encouragement and Stefan Wagenpfeil, Ph.D. (Department of Biometry, Epidemiology, and Medical Informatics, University Medical Center, Homburg (Saar), Germany), for his statistical support. This study contains data taken from the thesis presented by Nathalie Heim (Department of Anesthesiology, Intensive Care, and Pain Therapy, University Medical Center) as part of the requirements for the obtention of the degree "Doctor of Medicine" at Saarland University Medical Center and Saarland University Faculty of Medicine.

The data analysis work performed in this article (Dr. Baumbach) was supported by Deutsche Forschungsgemeinschaft (Bonn, Germany) within the Collaborative Research Center (Sonderforschungsbereich) SFB 876 "Providing Information by Resource-Constrained Analysis," project TB1 "Resource-Constrained Analysis of Spectrometry Data." All other funding was provided from department sources.

\section{Competing Interests}

The authors declare no competing interests.

\section{Correspondence}

Address correspondence to Dr. Fink: Department of Anesthesiology, Intensive Care, and Pain Therapy, Saarland University Medical Center, Kirrbergerstr., D-66421 Homburg (Saar), Germany. tobias.fink@uks.eu. Information on purchasing reprints may be found at www.anesthesiology.org or on the masthead page at the beginning of this issue. Anesthesiology's articles are made freely accessible to all readers, for personal use only, 6 months from the cover date of the issue.

\section{References}

1. Westhoff M, Litterst $\mathrm{P}$, Maddula S, Bödeker B, Rahmann S, Davies AN, Baumbach JI: Differentiation of chronic obstructive pulmonary disease (COPD) including lung cancer from healthy control group by breath analysis using ion mobility spectrometry. Int J Ion Mobil Spec 2010; 13:131-9

2. Westhoff M, Litterst P, Madulla S, Bödeker B, Baumbach JI: Statistical and bioinformatical methods to differentiate chronic obstructive pulmonary disease (COPD) including lung cancer from healthy control by breath analysis using ion mobility spectrometry. Int J Ion Mobil Spec 2011; 14:139-49

3. Bessa V, Darwiche K, Teschler H, Sommerwerck U, Rabis T, Baumbach JI, Freitag L: Detection of volatile organic compounds (VOCs) in exhaled breath of patients with chronic obstructive pulmonary disease (COPD) by ion mobility spectrometry. In J Mobil Spec 2011; 14:7-13

4. Schubert JK, Müller WP, Benzing A, Geiger K: Application of a new method for analysis of exhaled gas in critically ill patients. Intensive Care Med 1998; 24:415-21

5. Baumbach JI, Westhoff M: Ion mobility spectrometry to detect lung cancer and airway infection. Spectroscopy Europe 2006; $18: 22-7$

6. Westhoff M, Litterst P, Freitag L, Urfer W, Bader S, Baumbach JI: Ion mobility spectrometry for the detection of volatile organic compounds in exhaled breath of patients with lung cancer: Results of a pilot study. Thorax 2009; 64:744-8

7. Dwivedi P, Puzon G, Tam M, Langlais D, Jackson S, Kaplan K, Siems WF, Schultz AJ, Xun L, Woods A, Hill HH Jr: Metabolic profiling of Escherichia coli by ion mobility-mass spectrometry with MALDI ion source. J Mass Spectrom 2010; 45:1383-93

8. Maddula S, Blank LM, Schmid A, Baumbach JI: Detection of volatile metabolites of Escherichia coli by multi capillary column coupled ion mobility spectrometry. Anal Bioanal Chem 2009; 394:791-800

9. Purkhart R, Köhler H, Liebler-Tenorio E, Meyer M, Becher G, Kikowatz A, Reinhold P: Chronic intestinal Mycobacteria infection: Discrimination via VOC analysis in exhaled breath and headspace of feces using differential ion mobility spectrometry. J Breath Res 2011; 5:027103

10. Jünger $M$, Vautz $W$, Kuhns $M$, Hofmann L, Ulbricht $S$, Baumbach JI, Quintel M, Perl T: Ion mobility spectrometry for microbial volatile organic compounds: A new identification tool for human pathogenic bacteria. Appl Microbiol Biotechnol 2012; 93:2603-14

11. Baumbach JI: Ion mobility spectrometry coupled with multicapillary columns for metabolic profiling of human breath. J Breath Res 2009; 3:034001

12. Baumbach JI, Eiceman GA: Ion mobility spectrometry: Arriving on site and moving beyond a low profile. Appl Spectrosc 1999; 53:338A-55A

13. Borsdorf H, Eiceman GA: Ion mobility spectrometry principles and applications. Appl Spectrosc Rev 2006; 41:323-75

14. Eiceman GA, Stone JA: Ion mobility spectrometers in national defence. Anal Chem 2004; 76:390A-7A

15. Guamán AV, Carreras A, Calvo D, Agudo I, Navajas D, Pardo A, Marco S, Farré R: Rapid detection of sepsis in rats through volatile organic compounds in breath. J Chromatogr B Analyt Technol Biomed Life Sci 2012; 881-882:76-82

16. Fink T, Heymann P, Taha-Melitz S, Taha A, Wolf B, Rensing $\mathrm{H}$, Volk T, Mathes AM: Dobutamine pretreatment improves survival, liver function, and hepatic microcirculation after polymicrobial sepsis in rat. Shock 2013; 40:129-35

17. Scheiermann P, Hoegl S, Revermann M, Ahluwalia D, Zander J, Boost KA, Nguyen T, Zwissler B, Muhl H, Hofstetter C: Cecal ligation and incision: An acute onset model of severe sepsis in rats. J Surg Res 2009; 151:132-7

18. Rensing H, Jaeschke H, Bauer I, Pätau C, Datene V, Pannen $\mathrm{BH}$, Bauer M: Differential activation pattern of redox-sensitive transcription factors and stress-inducible dilator systems heme oxygenase- 1 and inducible nitric oxide synthase in hemorrhagic and endotoxic shock. Crit Care Med 2001; 29:1962-71

19. Jellestad L, Fink T, Pradarutti S, Kubulus D, Wolf B, Bauer I, Thiemermann C, Rensing H: Inhibition of glycogen synthase kinase (GSK)-3- $\beta$ improves liver microcirculation and hepatocellular function after hemorrhagic shock. Eur J Pharmacol 2014; 724:175-84

20. Wolf A, Baumbach JI, Kleber A, Maurer F, Maddula S, Favrod P, Jang M, Fink T, Volk T, Kreuer S: Multi-capillary columnion mobility spectrometer (MCC-IMS) breath analysis in 
ventilated rats: A model with the feasibility of long-term measurements. J Breath Res 2014; 8:016006

21. Mylotte JM, Tayara A: Blood cultures: Clinical aspects and controversies. Eur J Clin Microbiol Infect Dis 2000; 19:157-63

22. Sankar V, Webster NR: Clinical application of sepsis biomarkers. J Anesth 2013; 27:269-83

23. Schaub N, Frei R, Müller C: Addressing unmet clinical needs in the early diagnosis of sepsis. Swiss Med Wkly 2011; 141:w13244

24. Vincent JL, Donadello K, Schmit X: Biomarkers in the critically ill patient: C-reactive protein. Crit Care Clin 2011; 27:241-51

25. Shafazand S, Weinacker AB: Blood cultures in the critical care unit: Improving utilization and yield. Chest 2002; 122:1727-36

26. Casserly B, Read R, Levy MM: Multimarker panels in sepsis. Crit Care Clin 2011; 27:391-405

27. Ligor T, Ligor M, Amann A, Ager C, Bachler M, Dzien A Buszewski B: The analysis of healthy volunteers' exhaled breath by the use of solid-phase microextraction and GC-MS. J Breath Res 2008; 2:046006

28. Phillips M, Herrera J, Krishnan S, Zain M, Greenberg J, Cataneo RN: Variation in volatile organic compounds in the breath of normal humans. J Chromatogr B Biomed Sci Appl 1999; 729:75-88

29. Vautz W, Nolte J, Bufe A, Baumbach JI, Peters M: Analyses of mouse breath with ion mobility spectrometry: A feasibility study. J Appl Physiol (1985) 2010; 108:697-704

30. Filipiak W, Sponring A, Baur MM, Filipiak A, Ager C, Wiesenhofer H, Nagl M, Troppmair J, Amann A: Molecular analysis of volatile metabolites released specifically by Staphylococcus aureus and Pseudomonas aeruginosa. BMC Microbiol 2012; 12:113

31. Lanza-Jacoby S, Rosato E, Braccia G, Tabares A: Altered ketone body metabolism during gram-negative sepsis in the rat. Metabolism 1990; 39:1151-7
32. Ohtoshi M, Jikko A, Asano M, Uchida K, Ozawa K, Tobe $\mathrm{T}$ : Ketogenesis during sepsis in relation to hepatic energy metabolism. Res Exp Med (Berl) 1984; 184:209-19

33. Pailla K, El-Mir MY, Cynober L, Blonde-Cynober F: Cytokinemediated inhibition of ketogenesis is unrelated to nitric oxide or protein synthesis. Clin Nutr 2001; 20:313-7

34. Marcondes-Braga FG, Gutz IG, Batista GL, Saldiva PH, AyubFerreira SM, Issa VS, Mangini S, Bocchi EA, Bacal F: Exhaled acetone as a new biomaker of heart failure severity. Chest 2012; 142:457-66

35. Schubert JK, Miekisch W, Birken T, Geiger K, NöldgeSchomburg GF: Impact of inspired substance concentrations on the results of breath analysis in mechanically ventilated patients. Biomarkers 2005; 10:138-52

36. Van den Velde S, Nevens F, Van Hee P, van Steenberghe D, Quirynen M: GC-MS analysis of breath odor compounds in liver patients. J Chromatogr B Analyt Technol Biomed Life Sci 2008; 875:344-8

37. Seok J, Warren HS, Cuenca AG, Mindrinos MN, Baker HV, Xu W, Richards DR, McDonald-Smith GP, Gao H, Hennessy L, Finnerty CC, López CM, Honari S, Moore EE, Minei JP, Cuschieri J, Bankey PE, Johnson JL, Sperry J, Nathens AB, Billiar TR, West MA, Jeschke MG, Klein MB, Gamelli RL, Gibran NS, Brownstein BH, Miller-Graziano C, Calvano SE, Mason PH, Cobb JP, Rahme LG, Lowry SF, Maier RV, Moldawer LL, Herndon DN, Davis RW, Xiao W, Tompkins RG; Inflammation and Host Response to Injury, Large Scale Collaborative Research Program: Genomic responses in mouse models poorly mimic human inflammatory diseases. Proc Natl Acad Sci U S A 2013; 110:3507-12 